\title{
THE DIVERSITY OF SYMBIODINIACEAE HOSTED BY Palythoa tuberculosa FOUND AT THE EDGE OF THE SOUTH CHINA SEA
}

\author{
WEE HIN BOO*1, LAU YEE WAH ${ }^{1}$, SOONG KERYEA ${ }^{2,3}$ AND REIMER JAMES DAVIS ${ }^{1,4}$ \\ ${ }^{1}$ Graduate School of Engineering and Science, University of the Ryukyus, Okinawa, Japan. ${ }^{2}$ Department of Oceanography, \\ ${ }^{3}$ Asia-Pacific Ocean Research Center, National Sun Yat-Sen University, Kaohsiung, Taiwan. ${ }^{4}$ Tropical Biosphere Research \\ Center, University of the Ryukyus, Okinawa, Japan.
}

*Corresponding author: takheru@gmail.com

Submitted: 22 August 2019 Accepted: 5 October 2019

http://doi.org/10.46754/jssm.2020.06.006

\begin{abstract}
The Symbiodiniaceae genera composition hosted by the zooxanthellate zoantharian Palythoa tuberculosa is well documented in some parts of the Indo-Pacific region. Nevertheless, there are limited studies when it comes to the South China Sea (SCS), and no reports from the northern half of this region are available. This study examined Symbiodiniaceae diversity hosted by P. tuberculosa around Dongsha Atoll, in the north of the SCS. Samples of P. tuberculosa were collected inside and outside of the atoll. Phylogenetic analyses were conducted using sequences of the conservative internal transcribed spacer region 2 of rDNA (ITS2) and the hypervariable non-coding region of the chloroplast psbA gene ( $\left.\mathrm{psbA}^{\mathrm{ncr}}\right)$. Cladocopium was the dominant Symbiodiniaceae genus found in Dongsha, with only one Durusdinium-hosting P. tuberculosa colony found within the atoll. $\mathrm{psbA}^{\text {ncr }}$ results showed three Cladocopium lineages previously recorded in Okinawa (lineages 1, 2 and 3 sensu Noda et al., 2017). An experiment was set up outside the atoll to compare temperature fluctuations caused by internal waves, and the host-symbiont relationships found on spurs $(\mathrm{n}=27$, depth $=5.95 \pm 0.23 \mathrm{~m})$ and within grooves $(\mathrm{n}=27$, depth $=8.11 \pm 0.47 \mathrm{~m})$. Our results showed that there were no significant differences of Cladocopium lineages among the $P$. tuberculosa found at spurs and grooves despite significant differences in water temperature $(\mathrm{p}<0.001)$. Our results show that P. tuberculosa is flexible with Cladocopium lineages hosted, and that the internal wave regime at Dongsha Atoll apparently did not affect the host-symbiont relationship, at least in the spurs and grooves.
\end{abstract}

Keywords: Symbiodiniaceae, Palythoa tuberculosa, Dongsha Atoll, spurs and grooves

\section{Introduction}

Recently, the Symbiodiniaceae family (previously genus Symbiodinium) has been reevaluated because of its high level of diversity, which is higher than previously thought (LaJeunesse et al., 2018). In addition, the application of hypervariable non-coding plastid minicircle region sequences of the chloroplast psbA gene $\left(\mathrm{psbA}^{\mathrm{ncr}}\right)$ as a DNA marker has improved the resolution of delineating lineages to a finer level besides using the more conservative internal transcribed spacer region 2 (ITS2) of nuclear ribosomal DNA (Moore et al., 2003; LaJeunesse \& Thornhill, 2011). Many studies have shown that $\mathrm{psbA}^{\text {ncr }}$ can discern different lineages of Symbiodiniaceae, even when differences were not detected between ITS2 sequences, and in some cases, the physical distance between specimens may be as little as
200 m (Noda et al., 2017; Reimer et al., 2017a; Wee et al., 2019). Hence, ecological studies of the host-Symbiodiniaceae (henceforth known as holobiont) relationship are now possible at finer genetic and geographic scales than previously possible.

Palythoa tuberculosa (Esper, 1805) (Anthozoa: Hexacorallia: Zoantharia) is a ubiquitous sessile marine cnidarian, which can be found in temperate to tropical waters of the Indo-Pacific Ocean (Burnett, 2002; Reimer et al., 2008; Reimer \& Todd, 2009; Irei et al., 2011; Reimer et al., 2017b; 2017c). Aside from having a wide distribution, $P$. tuberculosa is present in marine environments beyond the tolerance limits of most zooxanthellate hexacorals, such as near estuaries, on acidified reefs, in intertidal zones, and in relatively hot areas (Inoue et al., 2013; Yang et al., 2013; Reimer et al., 2015; Reimer 
et al., 2017a). Their physiological resilience is due to their highly plastic colony form, a lack of calcium carbonate skeletal structure, thick and highly developed coenenchyme, and their active heterotrophic ability (Reimer, 1971; Fabricius \& Metzner, 2004; Reimer \& Todd, 2009; Ong et al., 2012). Furthermore, $P$. tuberculosa is one of the easiest zoantharians to identify in the field (Reimer, 2010) and they host symbiotic dinoflagellate algae of the family Symbiodiniaceae (Dinophyceae: Suessiales) (Burnett, 2002; Ono et al., 2008). The high resilience and wide distribution of P. tuberculosa have encouraged many studies on Symbiodiniaceae diversity in various environments and geographical areas (Burnett, 2002; Reimer et al., 2013; Noda et al., 2017; Reimer et al., 2017a; Wee et al., 2019). Hence, they are often utilized as a model to study the physiology and ecology of this relatively understudied zoantharian group (Shiroma \& Reimer, 2010; Polak et al., 2011; Ong et al., 2012; Noda et al., 2017).

P. tuberculosa reportedly exists in large numbers around Dongsha Atoll (20.41'15" $\mathrm{N} ; 116^{\circ} 48^{\prime} 42^{\prime \prime}$ E) (Reimer et al., 2017b). The atoll is $45 \mathrm{~km}$ in diameter and is situated on the northern edge of the South China Sea. The nearest land from the atoll is approximately $250 \mathrm{~km}$ away (Chou, 2013). A research station, Dongsha Atoll Research Station (DARS), is located at the inner west island of the atoll (Figure 1). Water temperature inside the atoll is 1 to $2{ }^{\circ} \mathrm{C}$ warmer than the outside (Chou, 2013). However, the outer atoll temperature has wide daily fluctuations of up to almost $8^{\circ} \mathrm{C}$ due to the influence of internal waves, which bring nutrient-rich cold water from the deep open ocean to the forereef via upwelling (Chang et al., 2006; Wang et al., 2007).

In a previous study, $P$. tuberculosa has been reported from both the spurs and grooves of the forereefs of Dongsha Atoll (Reimer et al., 2017b). This shows that this zoantharian can survive the periodic upwelling of cold-water internal waves. In this study, we aim to examine if the resilience of the holobiont is due to association with certain Symbiodiniaceae. We examined if there is any difference of the Symbiodiniaceae at the spurs and grooves due to the channeling of internal waves and differing environments. Real time logging of the water temperature and light intensity at the spurs and grooves have been conducted to compare the two sites.

\section{Materials and Methods}

Three survey trips were conducted at the atoll from November 27 to December 8, 2017, April 20 to May 4, 2018, and June 6 to June 13, 2019. The first survey mainly focused on the inner atoll, the second survey was at the northwest side of the outer atoll (Figure 1), and the final survey involved the retrieval of data loggers installed at the inner atoll. In the 2017 trip, five P. tuberculosa specimens were collected by snorkeling at the southeast coast of the island $\left(20^{\circ} 41^{\prime} 48.17^{\prime \prime} \mathrm{N}, 116^{\circ} 43^{\prime} 59.20^{\prime \prime} \mathrm{E}\right)$. HOBO Pendant ${ }^{\circledR}$ Temperature/Light 64K Data Loggers (OneTemp, Richmond, Adelaide, Australia) were deployed at the area. Approximately, 2 $\mathrm{cm}^{2}$ of $P$. tuberculosa specimens were collected with a knife. The specimens were preserved individually on land and stored in absolute ethanol (99.5\%) and sent back to the University of the Ryukyus (UoR) in Japan for analyses.

The 2018 trip was designed to focus on $P$. tuberculosa in spurs and grooves at the northwest outer atoll $\left(20^{\circ} 46^{\prime} 17.46^{\prime \prime} \mathrm{N}\right.$; $116^{\circ} 46^{\prime} 03.42^{\prime \prime}$ E). Six sets of adjacent spurs (depth $=5.95 \pm 0.23 \mathrm{~m})$ and grooves $(8.11 \pm 0.47$ $\mathrm{m}$ ) were chosen (Figure 2), each tagged with a HOBO Pendant ${ }^{\circledR}$ Temperature/Light 64K Data Logger. The loggers were set at 10-minute logging intervals from April 20 to April 30, 2018. Five $P$. tuberculosa colonies near each logger were collected at each spur and groove, where a total of 60 specimens were collected. Specimens were fixed in absolute ethanol (99.5\%) and sent to UoR for analyses. Genomic DNA of the specimens were extracted using the Qiagen DNeasy Blood and Tissue extraction kit (Qiagen, Tokyo, Japan). Symbiodiniaceae DNA was amplified via polymerase chain reaction (PCR) using two sets of primers targeting DNA regions 
in different organelles: the conservative ITS2 of nuclear ribosomal DNA and the hypervariable

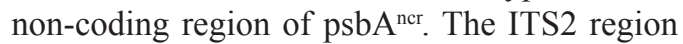
was amplified using the primers zITSf ( $5^{\prime}-\mathrm{CCG}$ GTG AAT TAT TCG GAC TGACGC AGT-3') and ITS4 (5'-TCC TCC GCT TAT TGATAT GC-3') (White et al., 1990; Rowan \& Powers, 1991; Hunter et al., 1997); while psbA $^{\text {ncr }}$ was amplified using the primers 7.4-Forw (5'-GCA TGA AAG AAA TGC ACA CAA CTT CCC3') and 7.8-Rev (5'-GGT TCT CTT ATT CCA TCA ATA TCT ACT G-3') (Moore et al., 2003; LaJeunesse \& Thornhill, 2011).

The PCR mixes were composed of 0.5-1.0 $\mu \mathrm{l}$ of genomic DNA, $10.0 \mu \mathrm{l}$ of HotStarTaq Plus Master Mix (Qiagen, Tokyo, Japan), $1.0 \mu \mathrm{l}$ of each primer (10 pmol), $1.0 \mu \mathrm{l} \mathrm{MgCl} 2(25 \mathrm{mmol})$, $0.5 \mu \mathrm{l}$ Bovine Serum Albumin $(20 \mathrm{mg} / \mathrm{ml}), 1.5$ $\mu \mathrm{l}$ Coral Load and topped up to the maximum of $20 \mu \mathrm{l}$ with autoclaved reverse-osmosis water. Thermocycle conditions were modified from Noda et al. (2017). For amplification of ITS2, the cycle began at $95.0{ }^{\circ} \mathrm{C}$ for five minutes, followed by 35 cycles of denaturation at 94.0 ${ }^{\circ} \mathrm{C}$ for $30 \mathrm{~s}$, annealling at $51.0^{\circ} \mathrm{C}$ for $45 \mathrm{~s}$, and elongation at $72.0{ }^{\circ} \mathrm{C}$ for $2 \mathrm{~min}$ before a final extension at $72.0^{\circ} \mathrm{C}$ for $10 \mathrm{~min}$. For $\mathrm{psbA}^{\text {ncr, }}$, the cycle began at $95.0^{\circ} \mathrm{C}$ for $5 \mathrm{~min}$, followed by 40 cycles of $94.0^{\circ} \mathrm{C}$ for $10 \mathrm{~s}, 55.0^{\circ} \mathrm{C}$ for 30 $\mathrm{s}$, and $72.0^{\circ} \mathrm{C}$ for $2 \mathrm{~min}$ before a final extension at $72.0{ }^{\circ} \mathrm{C}$ for $10 \mathrm{~min}$. The products were sent for sequencing in both directions (Fasmac, Kanagawa, Japan).

Both directions of the ITS2 sequences were checked and aligned manually to form a consensus sequence using BioEdit (Hall, 1999). No consensus sequence was produced with $\mathrm{psbA}^{\text {ncr }}$ as the hypervariable region made consensus impossible (Hawkins et al., 2016; Noda et al., 2017; Kunihiro \& Reimer, 2018). The compiled sequences of ITS2, forward $\mathrm{psbA}^{\text {ncr }}$ and reverse $\mathrm{psbA}^{\text {ncr }}$ were aligned separately in MEGA X (Kumar et al., 2018). Archived GenBank sequences (11 sequences) of Cladocopium, Durusdinium and Effrenium were obtained and included in the ITS2 alignment as references. The references for forward $\mathrm{psbA}^{\mathrm{ncr}}$ sequences were obtained from Noda et al. (2017), which were identified into four lineages: lineage 1 to 4 . In total, 57 (597bp length), 38 (251bp), and 51 (174bp) sequences were used in the alignments of ITS2, forward $\mathrm{psbA}^{\mathrm{ncr}}$ and reverse $\mathrm{psbA}^{\mathrm{ncr}}$, respectively.

Maximum likelihood (ML) and Bayesian inference (BI) phylogenetic trees were constructed based on the alignments of ITS2 and $\mathrm{psbA}^{\mathrm{ncr}}$. The best substitution methods for ML and BI were chosen based on the Neighbour Joining (NJ) tree reference under the automatic model selection of MEGA. Kimura-2 and JukeCantor model with 1000 bootstraps at uniform rates were utilized to construct ML trees of ITS2 and psbA ${ }^{\text {ncr }}$ (Hasegawa et al., 1985). The MrBayes version 3.2.6 x64 (Huelsenbeck \& Ronquist, 2001) software was used to construct BI phylogenetic trees of ITS2 (chain length $=5,000,000$; burn-in $=1,250,000$ ) and psbA $^{\text {ncr }}$ (chain length $=15,000,000$; burn-in $=$ $3,750,000)$.

Data from the HOBO loggers were extracted and averaged based on the inner atoll and outer atoll (spurs and grooves) grouping. Daily average temperature differences of all three categories were calculated. Light intensity data at night with values equal to 0 lux were removed for all categories. Friedman tests were conducted for average temperature $\left({ }^{\circ} \mathrm{C}\right)$ and light intensity (lux) data, and post-hoc Wilcoxon pairwise tests with Holm correction were conducted for results that were significantly different $(p<0.05)$.

\section{Results}

Based on ITS2 (Figure 3), all P. tuberculosa samples at the spurs and grooves $(\mathrm{n}=53)$, and most of the inner atoll $(\mathrm{n}=3 / 4)$, were found to host of Cladocopium zooxanthellae (C1) $(\mathrm{ML}=$ $99 \%, \mathrm{BI}=0.97)$. Only one colony at the inner atoll hosted the Durusdinium symbiont (ML = $99 \%, \mathrm{BI}=1.00$ ). The $\mathrm{psbA}^{\mathrm{ncr}}$ region examination was restricted to only Cladocopium symbionts (Figure 4) and based on the $\mathrm{psbA}^{\text {ncr }}$ forward sequences (Figure 4a), three Cladocopium 
lineages were found, all of which had been previously recorded in southern Japan (Noda $e t$ al., 2017). Two lineages were dominant: lineage $1(\mathrm{n}=24 ; \mathrm{ML}=61 \%, \mathrm{BI}=1.00)$ and lineage 2 $(\mathrm{n}=12 ; \mathrm{ML}=51 \%, \mathrm{BI}=1.00)$ sensu Noda et al. (2017) (Noda et al., 2017). Furthermore, there was also a small number of lineage $3(\mathrm{n}=2$; ML $=65 \%, \mathrm{BI}=0.97)$ sensu Noda et al. (2017) (Noda et al., 2017). Additionally, reverse sequences all agreed with the forward sequences for lineage 1 $(\mathrm{n}=28 ; \mathrm{ML}=99 \%, \mathrm{BI}=1.00)$, lineage $2(\mathrm{n}=$
$20 ; \mathrm{ML}=65 \%, \mathrm{BI}=0.99)$ and lineage $3(\mathrm{n}=3$; $\mathrm{ML}=99 \%, \mathrm{BI}=1.00)($ Figure $4 \mathrm{~b})$. There were 54 P. tuberculosa colonies hosting Cladocopium identified based on forward and reverse $\mathrm{psb}^{\text {ncr }}$ sequences, with 27 each from the spurs and grooves (Figure 5). Lineage 1 was the dominant lineage at both spurs $(\mathrm{n}=14)$ and grooves $(\mathrm{n}=$ 17), followed by lineage 2 (spurs $=12$, grooves $=8$ ), and finally, lineage 3 (spurs $=1$, grooves $=2)$.
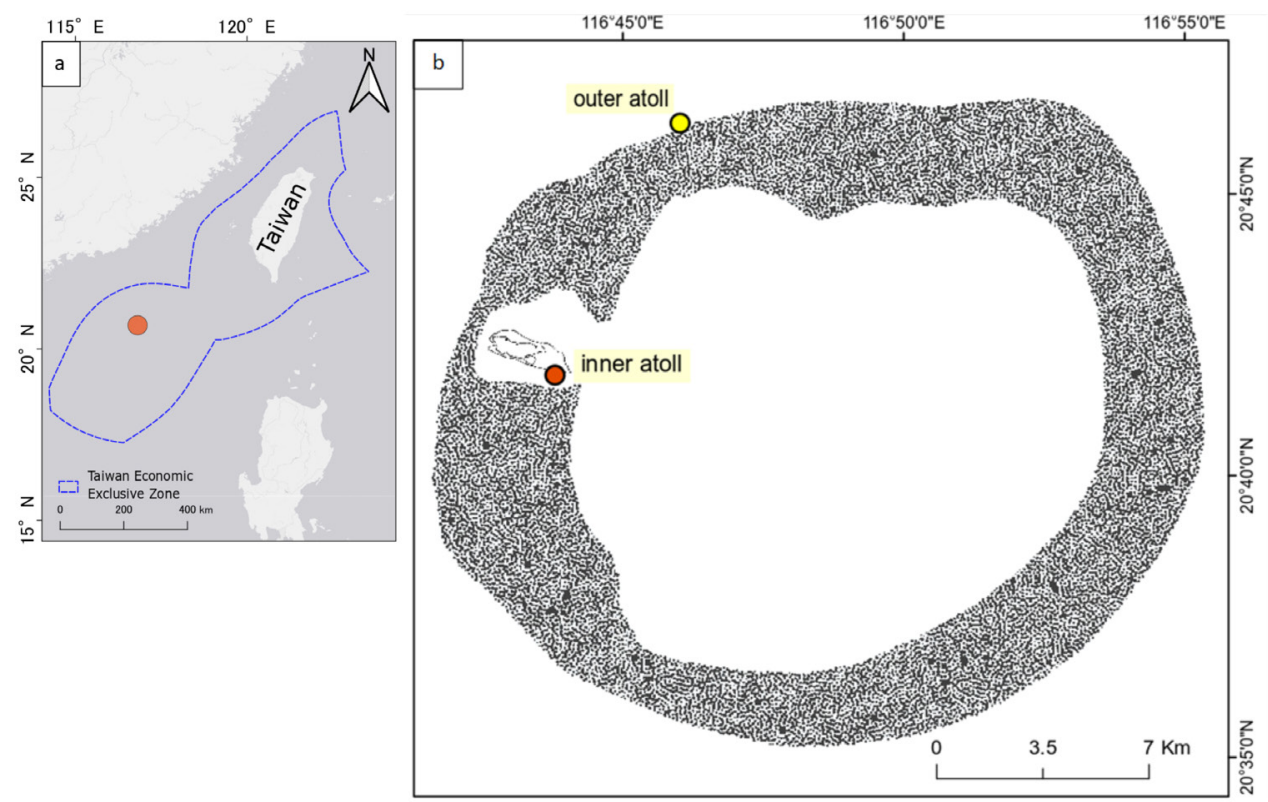

Figure 1: Map of (a) the location of Dongsha Atoll (indicated by orange dot), with the blue dotted line representing the Exclusive Economic Zone (EEZ) of Taiwan (Flanders Marine Institute, 2018), and (b) the sampling sites at the atoll; inner atoll (2017) and outer atoll (2018), the dotted marking represents the submerged atoll. 

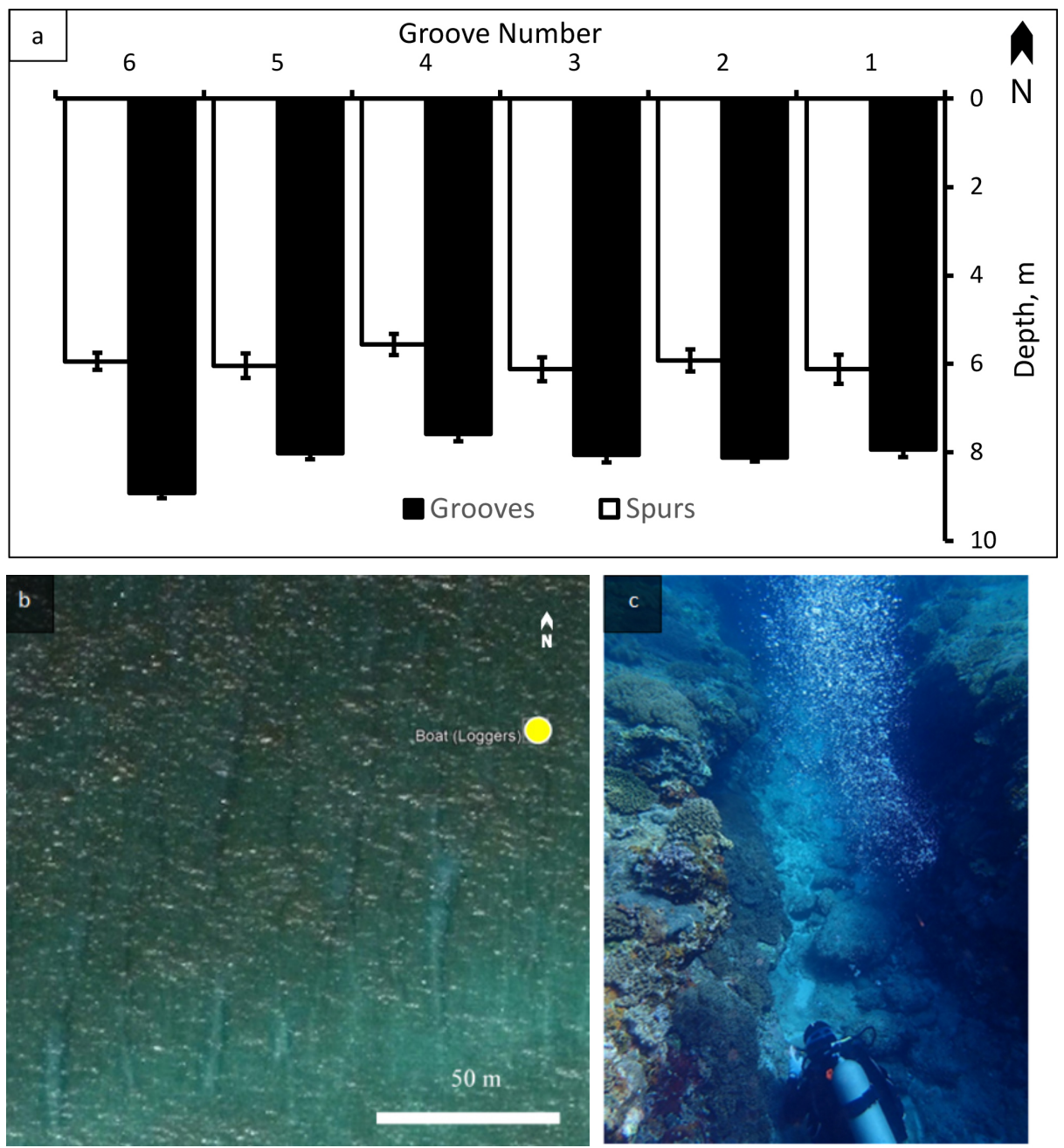

Figure 2: Study design of the spurs and grooves. (a) Average depths of Palythoa tuberculosa colonies sampled at the spurs (white) and grooves (black). The error bars represent standard deviations. (b) Aerial photograph of the spurs and grooves study site. The yellow dot represents the first groove tagged, and subsequent spurs and grooves were chosen westward (to the left) adjacent to the previous set. (c) Photograph of a researcher working in a groove, with spurs on each side.

The seawater temperature range was between $23.292^{\circ} \mathrm{C}$ (grooves: April 22) to 29.152 ${ }^{\circ} \mathrm{C}$ (inner atoll: April 30) (Figure 6a). The daily range of temperature fluctuation was between $\Delta 0.976^{\circ} \mathrm{C}$ (Inner atoll: April 20) to $\triangle 4.124^{\circ} \mathrm{C}$ (inner atoll: April 30). There were significant differences (Friedman: $\mathrm{X}^{2}=388.21$, $\mathrm{df}=2, \mathrm{p}<0.001)$ in temperature among the inner atoll $\left(26.924 \pm 0.749^{\circ} \mathrm{C}\right)$, spurs $\left(25.364 \pm 0.666^{\circ} \mathrm{C}\right)$ and grooves $\left(25.211 \pm 0.633^{\circ} \mathrm{C}\right)$. Post-hoc test
(Wilcoxon pairwise test with Holm correction) showed that there were significant differences between all categories, especially the inner and outer atoll sites $(\mathrm{p}<0.001)$. On the other hand, light intensity during the day ranged between 5.4 (grooves: April 26) to 39955.8 lux (inner atoll: April 27) (Figure 6b). There were significant differences (Friedman: $\mathrm{X}^{2}=62.01$, $\mathrm{df}=2, \mathrm{p}<0.001)$ in light intensity among the inner atoll (average $=7861.11$ lux), spurs 
(average $=3940.300$ lux) and grooves (average $=3464.87$ lux). Post-hoc test (Wilcoxon with Holm correction) showed that the inner atoll had significantly higher light intensity compared to the outer atoll sites $(p<0.001)$, whereas there was no significant difference between spurs and grooves in terms of light intensity $(p=0.117)$.

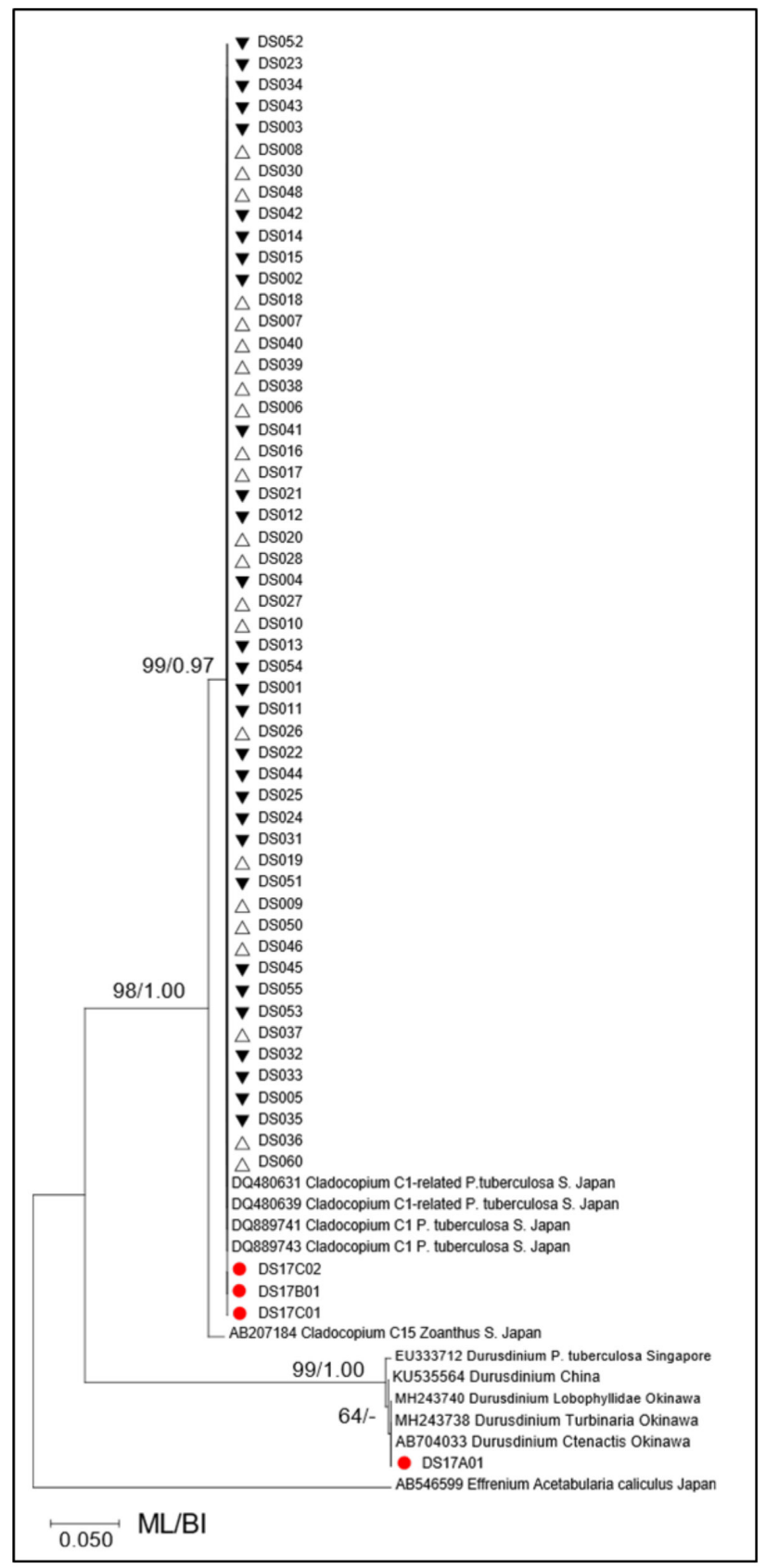

Figure 3: Phylogeny of Symbiodiniaceae hosted by P. tuberculosa found at Dongsha Atoll based on ITS2 region represented by maximum likelihood (ML) tree with ML bootstrap support and Bayesian inference (BI) posterior probability. Red dot $=$ inner atoll; white upper triangle $=$ spurs; black lower triangle $=$ grooves. 

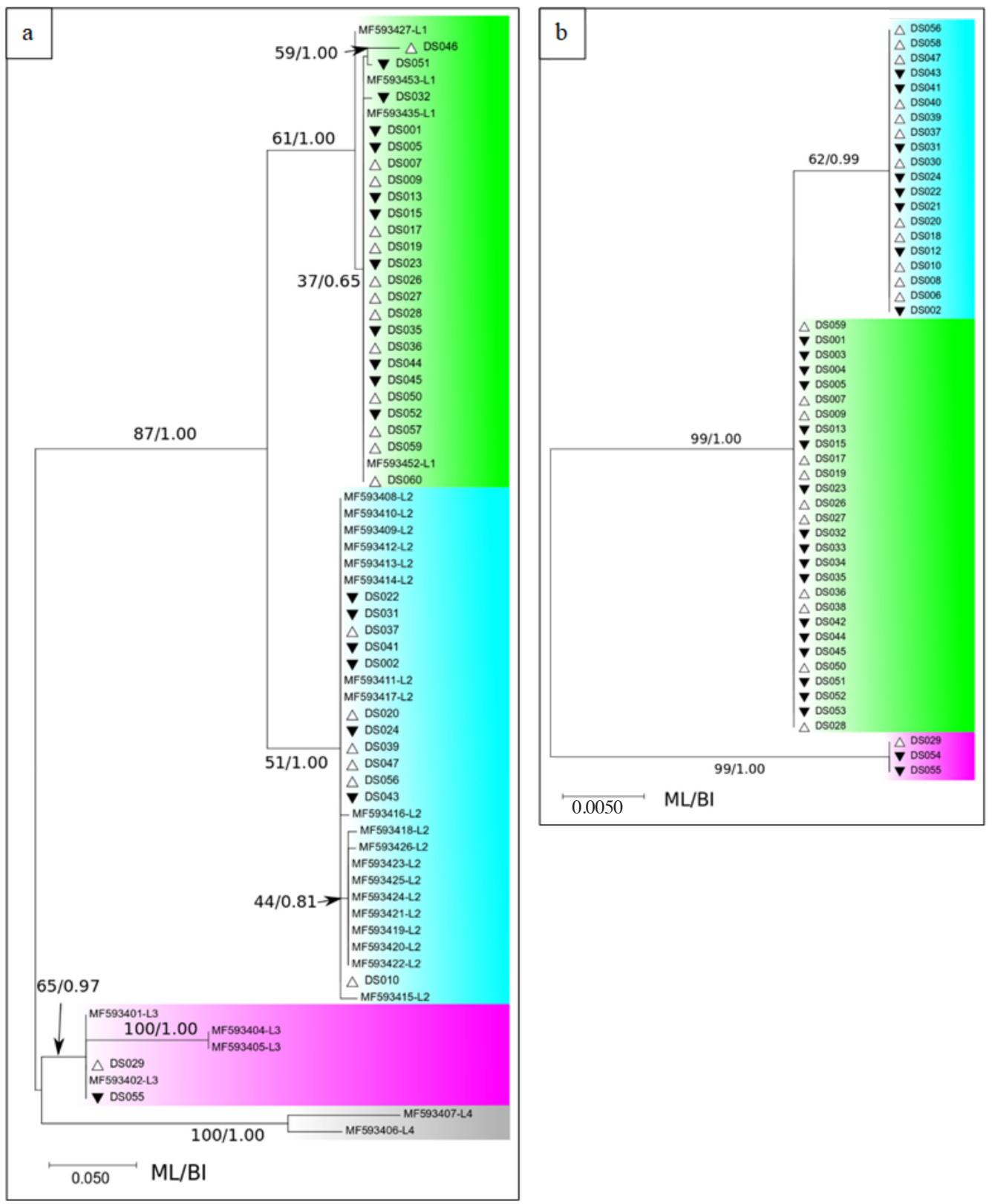

Figure 4: Phylogeny of Cladocopium psbA $^{\text {ncr }}$ lineages hosted by P. tuberculosa found at Dongsha Atoll based on (a) forward $\mathrm{psbA}^{\mathrm{ncr}}$ and (b) reverse $\mathrm{psbA}^{\text {ncr }}$ sequences represented by maximum likelihood (ML) phylogenies with ML bootstrap support and Bayesian inference (BI) posterior probability. White upper triangle $=$ spurs; black lower triangle $=$ grooves. Green $=$ lineage 1 ; blue $=$ lineage 2 ; purple $=$ lineage 3 ; grey $=$ lineage 4 . 


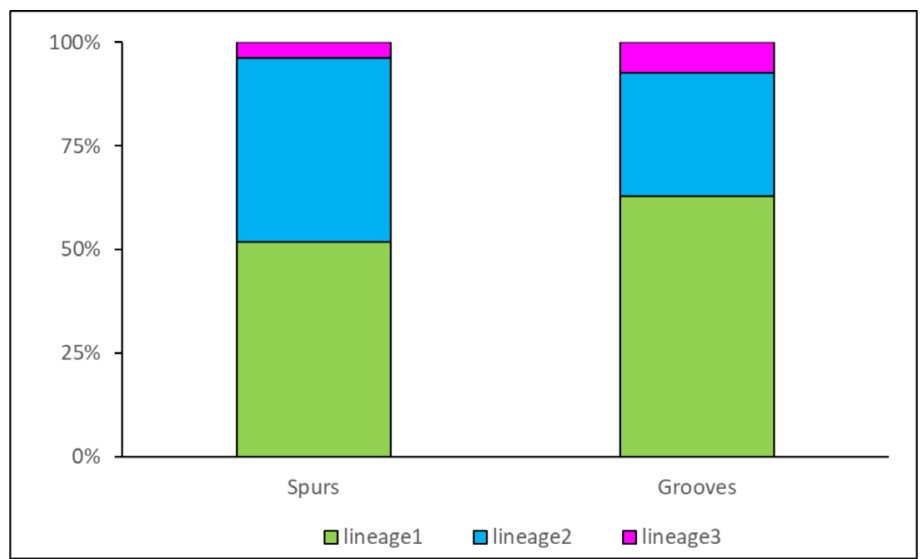

Figure 5: Cladocopium $\mathrm{psbA}^{\text {ncr }}$ lineage composition of spurs $(\mathrm{n}=27)$ and grooves $(\mathrm{n}=27)$. Green $=$ lineage 1 ; cyan $=$ lineage 2 ; purple $=$ lineage 3.
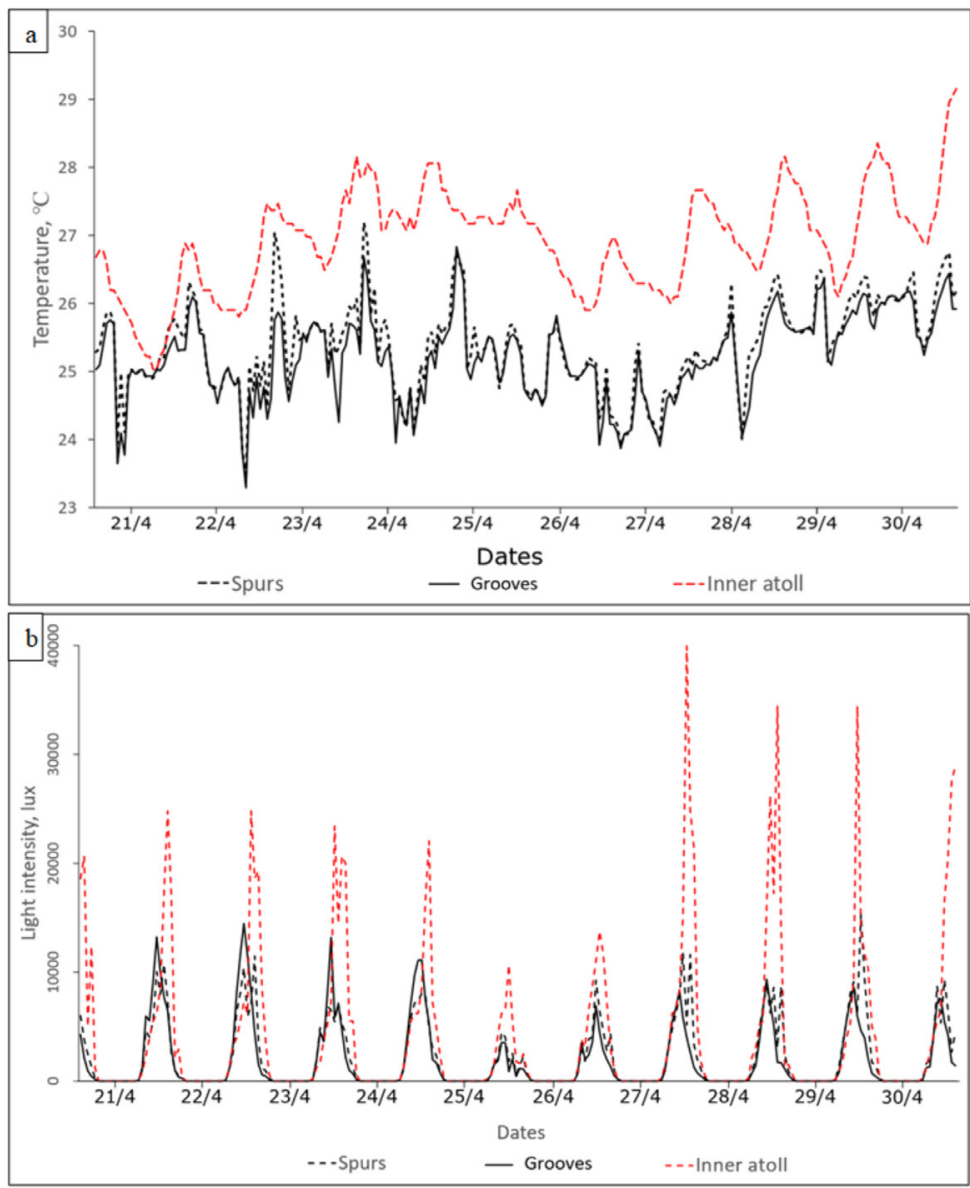

Figure 6: (a) Temperature $\left({ }^{\circ} \mathrm{C}\right.$ ) and (b) light intensity (Lux) fluctuations at the inner atoll, spurs and grooves of outer Dongsha Atoll from April 20 to 30, 2018. The red dotted line represents the inner atoll, black dotted line at the spurs and the black solid line is the grooves. 


\section{Discussion}

The Durusdinium symbiont was recorded only once at the inner atoll, while Cladocopium was predominant throughout the outer grooves and inner atoll. However, no $\mathrm{psbA}^{\text {ncr }}$ sequences were obtained from the Cladocopium specimens in the inner atoll, as amplification of the psbA region proved to be difficult, and thus, we could not speculate on the specific lineage present in these specimens. Durusdinium is generally thought to be a relatively thermotolerant genus of Symbiodiniaceae (Bongaerts et al., 2013; Tonk et al., 2013; Yuyama et al., 2016; Silverstein et al., 2017). This was reflected by the seawater temperature recorded at its habitat, which was significantly higher at the inner atoll. Previous records have also shown that the inner atoll is more turbid and warmer than the outer atoll (Chou, 2013). In our study, despite the higher turbidity, the light intensity in the inner atoll was significantly higher than the outer atoll due to the shallow locations where P. tuberculosa colonies were sampled $(<2 \mathrm{~m})$. Hence, $P$. tuberculosa colonies at the warmer inner atoll might host Durusdinium to improve the thermotolerance of the holobiont (Stat et al., 2013). However, due to the limited number of specimens collected from the inner atoll, our understanding of the Symbiodiniaceae in the inner atoll and the conclusions that could be drawn in this study were limited.

At the outer atoll, Cladocopium $\mathrm{psbA}^{\text {ncr }}$ lineages identified were reported in the same host (P. tuberculosa) from the Ryukyu Islands (Noda et al., 2017; Wee et al., 2019). Lineage 1 was known as a generalist lineage, while lineage 2 had been observed to be common in low salinity areas around Okinawa main island (Noda et al., 2017; Wee et al., 2019). However, due to low numbers of observations, little was known about lineage 3 (Noda et al., 2017). There was no significant difference in Symbiodiniaceae and Cladocopium psbA $^{\text {ncr }}$ lineages hosted by $P$. tuberculosa at the spurs and grooves, in contrast with what we initially hypothesized.

At the outer atoll, temperature results showed the spurs were significantly warmer than the grooves. However, the average differences between the two areas were relatively small $\left(0.153^{\circ} \mathrm{C}\right)$. Furthermore, the average daily water fluctuations at both spurs and grooves were less than $4^{\circ} \mathrm{C}$, approximately half of what was previously reported at the northwest outer atoll (Wang et al., 2007). On the other hand, there were no significant differences in light intensity between the spurs and grooves. Hence, holobionts at the spurs and grooves appeared to dwell in rather similar environments. Nevertheless, the present dataset covered a relatively short period (10 days), and longer term (e.g. one year) data would be needed for more robust comparison.

\section{Conclusion}

P. tuberculosa found at the outer atoll hosted only Symbiodiniaceae from genus Cladocopium, with three lineages. However, there was no significant distinction in Cladocopium lineage composition between the spurs and grooves. Seawater temperature fluctuations were observed, predominantly due to the upwelling of cold water by internal waves (Wang et al., 2007; Chen et al., 2010). Temperatures between the spurs and grooves were similar in range, but the spurs were slightly but significantly warmer than the grooves, as previously reported (Wang et al., 2007). Our results showed that $P$. tuberculosa was flexible with symbiodinian lineages at the spurs and grooves around Dongsha Atoll, although we observed no conclusive evidence that the internal waves affected the diversity of the host-symbiont relationship in these environments. On the other hand, this study recorded one occurrence of thermo-tolerant Symbiodiniaceae Durusdinium-hosting $P$. tuberculosa in the significantly warmer inner area of Dongsha Atoll (Chou, 2013).

\section{Acknowledgements}

This research was supported by Dongsha Atoll Research Station and Ministry of Science and Technology, Taiwan. The authors like to extend their appreciation to Hiroki Kise, Yi-Bei Liang 
Tam Di-Bing, Oscar Ng Kang-Ming, and Arthur Chang Cherng Shyang for their assistance.

\section{References}

Bongaerts, P., Frade, P.R., Ogier, J. J., Hay, K.B., Van Bleijswijk, J., Englebert, N., Vermeij, M.J., Bak, R. P., Visser, P. M. \& Hoegh-Guldberg, O. (2013). Sharing the slope: depth partitioning of agariciid corals and associated Symbiodinium across shallow and mesophotic habitats $(2-60 \mathrm{~m})$ on a Caribbean reef. BMC Evolutionary Biology, 13(205), 2-14.

Burnett, W. J. (2002). Longitudinal variation in algal symbionts (zooxanthellae) from the Indian Ocean zoanthid Palythoa caesia. Marine Ecology Progress Series, 234, 105109.

Chang, M. H., Lien, R. C., Tang, T. Y., D’Asaro, E. A., \& Yang, Y. J. (2006). Energy flux of nonlinear internal waves in northern South China Sea. Geophysical Research Letters, 33(3), L03607.

Chen, G. Y., Wu, R. J., \& Wang, Y. H. (2010). Interaction between internal solitary waves and an isolated atoll in the Northern South China Sea. Ocean Dynamics, 60(5), 12851292.

Chou, Y. (2013). Dongsha Atoll research Station-A steady research platform in South China Sea. Kuroshio Science, 10, 23-27.

Fabricius, K. E., \& Metzner, J. (2004). Scleractinian walls of mouths: Predation on coral larvae by corals. Coral Reefs, 23(2), 245-248.

Flanders Marine Institute. (2018). Maritime Boundaries Geodatabase: Maritime Boundaries and Exclusive Economic Zones (200NM). http://www.marineregions.org https://doi.org/10.14284/312.

Hall, T. A. (1999). BioEdit: a user-friendly biological sequence alignment editor and analysis program for Windows 95/98/NT. Nucleic Acids Symposium Series, 41(41), 95-98.
Hasegawa, M., Kishino, H., \& Yano, T. A. (1985). Dating of the human-ape splitting by a molecular clock of mitochondrial DNA. Journal of Molecular Evolution, 22(2), 160-174.

Hawkins, T. D., Hagemeyer, J. C., \& Warner, M. E. (2016). Temperature moderates the infectiousness of two conspecific Symbiodinium strains isolated from the same host population. Environmental Microbiology, 18(12), 5204-5217.

Huelsenbeck, J. P., \& Ronquist, F. (2001). MRBAYES: Bayesian inference of phylogenetic trees. Bioinformatics, 17(8), 754-755.

Hunter, C. L. (1997). The utility of ITS sequences in assessing relationships among zooxanthellae and corals. Proceedings of the 8th International Coral Reef Symposium, 2, 1599-1602.

Inoue, S., Kayanne, H., Yamamoto, S., \& Kurihara, H. (2013). Spatial community shift from hard to soft corals in acidified water. Nature Climate Change, 3(7), 683687.

Irei, Y., Nozawa, Y., \& Reimer, J. D. (2011). Distribution patterns of five zoanthid species in Okinawa Island, Japan. Zoological Studies, 50(4), 426-433.

Kumar, S., Stecher, G., Li, M., Knyaz, C., \& Tamura, K. (2018). MEGA X: molecular evolutionary genetics analysis across computing platforms. Molecular Biology and Evolution, 35(6), 1547-1549.

Kunihiro, S., \& Reimer, J. D. (2018). Phylogenetic analyses of Symbiodinium isolated from Waminoa and their anthozoan hosts in the Ryukyu Archipelago, southern Japan. Symbiosis, 76(3), 253-264.

LaJeunesse, T. C., \& Thornhill, D. J. (2011). Improved resolution of reef-coral endosymbiont (Symbiodinium) species diversity, ecology, and evolution through psbA non-coding region genotyping. PLoS ONE, 6(12), e29013. 
LaJeunesse, T. C., Parkinson, J. E., Gabrielson, P. W., Jeong, H. J., Reimer, J. D., Voolstra, C. R., \& Santos, S. R. (2018). Systematic revision of Symbiodiniaceae highlights the antiquity and diversity of coral endosymbionts. Current Biology, 28(16), 2570-2580.

Moore, R. B., Ferguson, K. M., Loh, W. K., Hoegh-Guldberg, O., \& Carter, D. A. (2003). Highly organized structure in the non-coding region of the psbA minicircle from clade C Symbiodinium. International Journal of Systematic and Evolutionary Microbiology, 53(6), 1725-1734.

Noda, H., Parkinson, J. E., Yang, S. Y., \& Reimer, J. D. (2017). A preliminary survey of zoantharian endosymbionts shows high genetic variation over small geographic scales on Okinawa-jima Island, Japan. PeerJ, 5, e3740.

Ong, C. W., Reimer, J. D., \& Todd, P. A. (2013). Morphologically plastic responses to shading in the zoanthids Zoanthus sansibaricus and Palythoa tuberculosa. Marine Biology, 160(5), 1053-1064.

Ono, S., Reimer, J. D., \& Tsukahara, J. (2008). Ecological survey of zooxanthellate zoanthid diversity (Hexacorallia: Zoantharia) from Kagoshima, Japan. Kuroshio Biosphere, 4, 1-16.

Polak, O., Loya, Y., Brickner, I., KramarskiWinter, E., \& Benayahu, Y. (2011). The widely-distributed Indo-Pacific zoanthid Palythoa tuberculosa: a sexually conservative strategist. Bulletin of Marine Science, 87(3), 605-621.

Reimer, A. A. (1971). Feeding behavior in the Hawaiian zoanthids Palythoa and Zoanthus. Pacific Science, 25, 512-520.

Reimer, J. D., Sinniger, F., \& Hickman, C. P. (2008). Zoanthid diversity (Anthozoa: Hexacorallia) in the Galapagos Islands: a molecular examination. Coral Reefs, 27(3), 641-654.
Reimer, J. D., \& Todd, P. A. (2009). Preliminary molecular examination of zooxanthellate zoanthid (Hexacorallia, Zoantharia) and associated zooxanthellae (Symbiodinium spp.) diversity in Singapore. Raffles Bulletin of Zoology, 22, 103-120.

Reimer, J. D. (2010). Key to field identification of shallow water brachycnemic zoanthids (Order Zoantharia: Suborder Brachycnemina) present in Okinawa. Galaxea, Journal of Coral Reef Studies, 12(1), 23-29.

Reimer, J. D., Irei, Y., Fujii, T., \& Yang, S. Y. (2013). Molecular analyses of shallowwater zooxanthellate zoanthids (Cnidaria: Hexacorallia) from Taiwan and their Symbiodinium spp. Zoological Studies, 52(1), 2-16.

Reimer, J. D., Wee, H. B., Put Jr, A., \& Hoeksema, B. W. (2015). Zoantharia (Cnidaria: Anthozoa: Hexacorallia) of the South China Sea and Gulf of Thailand: a species list based on past reports and new photographic records. Raffles Bulletin of Zoology, 63, 334-356.

Reimer, J. D., Herrera, M., Gatins, R., Roberts, M. B., Parkinson, J. E., \& Berumen, M. L. (2017a). Latitudinal variation in the symbiotic dinoflagellate Symbiodinium of the common reef zoantharian Palythoa tuberculosa on the Saudi Arabian coast of the Red Sea. Journal of Biogeography, 44(3), 661-73.

Reimer, J. D., Santos, M. E. A., Kise, H., Neo, M. L., Chen, C. A., \& Soong, K. (2017b). Diversity of Zoantharia (Anthozoa: Hexacorallia) at Dongsha Atoll in the South China Sea. Regional Studies in Marine Science, 12, 49-57.

Reimer, J. D., Montenegro, J., Santos, M. E., Low, M. E., Herrera, M., Gatins, R., Roberts, M. B. \& Berumen, M. L. (2017c). Zooxanthellate zoantharians (Anthozoa: Hexacorallia: Zoantharia: Brachycnemina) in the northern Red Sea. Marine Biodiversity, 47(4), 1079-1091. 
Rowan, R. O. B., \& Powers, D. A. (1991). A molecular genetic classification of zooxanthellae and the evolution of animalalgal symbioses. Science, 251(4999), 13481351.

Shiroma, E., \& Reimer, J. D. (2010). Investigations into the reproductive patterns, ecology, and morphology in the zoanthid genus Palythoa (Cnidaria: Anthozoa: Hexacorallia) in Okinawa, Japan. Zoological Studies, 49(2), 182-194.

Silverstein, R. N., Cunning, R., \& Baker, A. C. (2017). Tenacious D: Symbiodinium in clade $\mathrm{D}$ remain in reef corals at both high and low temperature extremes despite impairment. Journal of Experimental Biology, 220(7), 1192-1196.

Stat, M., Pochon, X., Franklin, E. C., Bruno, J. F., Casey, K. S., Selig, E. R., \& Gates, R. D. (2013). The distribution of the thermally tolerant symbiont lineage (Symbiodinium clade D) in corals from Hawaii: correlations with host and the history of ocean thermal stress. Ecology and Evolution, 3(5), 131729.

Tonk, L., Sampayo, E.M., Weeks, S., MagnoCanto, M., \& Hoegh-Guldberg, O. (2013). Host-specific interactions with environmental factors shape the distribution of Symbiodinium across the Great Barrier Reef. PLoS ONE, 8(7), e68533.

Wang, Y. H., Dai, C. F., \& Chen, Y. Y. (2007). Physical and ecological processes of internal waves on an isolated reef ecosystem in the South China Sea. Geophysical Research Letters, 34(18), 1-7.

Wee, H. B., Kurihara, H., \& Reimer, J. D. (2019). Reduced Symbiodiniaceae diversity in Palythoa tuberculosa at a heavily acidified coral reef. Coral Reefs, 38(2), 311-319.

White, T. J., Bruns, T., Lee, S. J., \& Taylor, J. L. (1990). Amplification and direct sequencing of fungal ribosomal RNA genes for phylogenetics. PCR Protocols: A Guide to Methods and Applications, 18, 315-22.

Yang, S. Y., Bourgeois, C., Ashworth, C. D., \& Reimer, J. D. (2013). Palythoa zoanthid 'barrens' in Okinawa: examination of possible environmental causes. Zoological Studies, 52(1), 1-12.

Yuyama, I., Nakamura, T., Higuchi, T., \& Hidaka, M. (2016). Different stress tolerances of juveniles of the coral Acropora tenuis associated with clades $\mathrm{C} 1$ and D Symbiodinium. Zoological Studies, 55(19), 2016-2055. 